\title{
Socio-Business Consideration of Garment Workers in Bangladesh: A Statistical Review
}

\author{
Naiem Jalal Uddin Ahmed ${ }^{1}$, Ms. Nasima ${ }^{2}$, Naznin Alam \\ ${ }^{1}$ Assistant Professor, Department of Business Administration, Stamford University Bangladesh, BANGLADESH \\ ${ }^{2,3}$ Lecturer, Department of Business Administration, Stamford University Bangladesh, BANGLADESH
}

\begin{abstract}
RMG sector is the most influential economic contributory sector in Bangladesh. Fifty percent and more revenue in GDP approximately are generated from this sector. Therefore, it is very much important to analyze the socio-business consideration of garment sector in Bangladesh. So far, since 80's garment industries had been booming in Bangladesh. These types of industries face challenges and take the advantage over different opportunities throughout more than three decades. Here, this paper suggested that the socio-economic as well as the business-statistical review of the garment industries in Bangladesh by providing some field research. This paper attempted to provide an overview of the industry in monitoring, standard of living, mix assessment and compliance (which is provided by foreign buyers) aspects.
\end{abstract}

Keyword: RMG, GDP, Garment Industry

\section{INTRODUCTION}

The Readymade Garments (RMG) sector ensures labor rights, labor standards, fair labor practices and a Code of Conduct in garment industries. This sector has a greater potential than any other sector to poverty reduction in Bangladesh. RMG sector has been becoming important in terms of employment, foreign exchange earnings and its contribution to Gross Domestic Product (GDP) gradually. Poor working conditions in the factories, lack of social compliance, and lack of security are serious concerns in the present situation of Bangladeshi garment industries since 2006. Compliance is defined as code of conduct, specification and or standard that must be followed by business organizations. Now it has led to labor unrest and damage to institutions and property as well as the valuable human lives. As a result, the garment industries now have become a potential discussed factor in Bangladesh. Hence, the readymade garments (RMG) sector is now facing a decline in demand. Recently the US government suspended Bangladesh from the Generalized System of Preferences (GSP). GSP allows dutyfree entry of over 5,000 goods to the US market from least developed countries like Bangladesh. This action is taken because of the failure to improve working conditions in the country by the Bangladesh government. The probable financial loss in terms of falling export seems very small in the short run. Now Bangladesh exports about $\$ 5$ billion worth of goods where mostly RMG products to the USA are every year. Therefore, the suspension from US GSP will account for a fall in export of about $0.8 \%$ for Bangladesh. 
Undoubtedly, the garments industry has a significant impact in the economy and image of Bangladesh. The garments industry is one of the two major foreign exchange generating sources, the other being remittance from expatriates. It is also providing employment to huge number of people especially women in Bangladesh who account for 90 percent of the work force in this industry. Due to the conservative norms and values that exist in the country, women are not able to work in all kinds of industries. The RMG sector has provided an excellent opportunity for them to get employment, bringing a significant change in the demographics of the workforce of the country. The employment opportunities in this sector are encouraging farmers in rural areas to discontinue farming and to join the garments industry. Women are leaving their employment in the informal sector where they mostly worked as housemaids. Facing hardship and poverty, these women who are often illiterate or having less than primary level education come to urban areas in search of work in garments industries for better living conditions. Many will argue that the living standards of the laborers are still below average, but we must say that after having job in RMG sectors they are living a better life than they used to live before.

In addition to the economic contribution of the readymade garments sector, the expansion of this industry has caused noticeable social changes by bringing more than 1.12 million women into labor force. It has given women the chance to be financially independent and have a voice in the family because now they can contribute financially. This economic contribution as well as empowerment of women has changed their status in the family. Most importantly, RMG sector produces a group of entrepreneurs of those a sizable number is female. A woman entrepreneur established one of the oldest export oriented garment factories named "Baishakhi Garments" in 1977. Many women are now holding top executive positions in RMG industry. One of them named Bibi Rasel is very much popular for her fashion house known as "Bibiyana" in Bangladesh.

Thus, RMG sector is not only contributing in earning foreign currencies but also creating employment opportunities for women that in turn can contribute in the socio-economic development of Bangladesh. Therefore, it is very much essential to assess the status of women workers in RMG sector to take appropriate strategies for facilitating as well as ensuring their rights so that this sector will become more convenient for them. This will encourage the women and provide them the opportunity to contribute in the development of Bangladesh.

In Bangladesh, the government had declared that the minimum salary of a garment worker would be 5500 taka. However, recently the higher authorities of the garment industries have declared to pay 5300 taka per employee. According to "International Trade Statistics" (2013) of World Trade Organization, Bangladesh is 8th in importing textile. In 2012, our country has imported 584 crore-dollar textile. Therefore, we can say the RMG sector is very much important to make our country internationally renowned.

\section{LITERATURE REVIEW}

RMG sector is the most profitable sector in Bangladesh. In many research papers, we see the negative sides of this sector. However, we know that this situation can be changed. Now, working conditions in the RMG sector are now making their standard better. Here, workers suffer various kinds of diseases due to the unhygienic environment also a number of workers are killed in different accidents like fire hazard and panicking. We have lost so many lives and we feel responsible for that. The international organizations have seen how cordial the people are to get rid of this horrible situation. Day by day, this situation is changing. As RMG sector is an important foreign exchange earning component so this 
type of inappropriate mechanism should be eradicated for protecting workers' rights and maintaining their safety. According to Qudus, Rashid and Dasgupta; the working conditions in this sector frequently violate international labor standards, and Codes of Conduct (Quddus, M. and Rashid, S.; 2000 and Dasgupta S., 2002). Alam (2004) suggested that regularity and strict monitoring by the government agency could overcome security problems of garment workers in Bangladesh. Sometimes, women workers face physical abuse and sexual harassment inside as well as outside the factories. Now, management is more concerned about the security of women workers. According to Kumar, garment workers are concerned with long working hours or double consecutive shifts, personally unsafe work environment, poor working conditions, wage and gender discrimination. In addition, the higher authorities treat the RMG workers as slaves, exploiting workers to increase their profit margins and keep their industry competitive to compete internationally (Kumar A., 2006). In Bangladesh, recruitment policies are highly informal because there is no a written formal contract or appointment letter. Hence, the workers have to lose their jobs at any time. However, fear of losing their jobs and lack of alternative job opportunities makes them unsatisfied (Bansari, 2010). As it is a very important sector to gain foreign currencies, so they should be given appointment letters. Now it is becoming more formal to join a garment factory than before.

According to Morshed, the key role of Cambodian labor unions in the RMG sector and as mediator's between workers and factory owners to settle disputes and discuss wages (Morshed, 2007). As per government's decision now in Bangladesh the higher authorities of garment industries are also going to pay 5300 taka per employee, which is much better wage than before. Now it has become regular incidents to injure, disable and dead from fire and building collapses in different garment factories (Majumder P, 1998), which is not desirable. People are now becoming more and more conscious day by day on this regard. The government, NGOs, international agencies, buyers and other stakeholder groups should work together with mandatory requirements as specified in the law, which is now happening. Hence, it is true that NGOs, civil society, trade unions and other stakeholders should work together to adopt the Code of Conduct for a viable and competitive RMG industry (Khan, 2006). On the basis of the "International Trade Statistics" by World Trade Organization, Bangladesh has become 8th for importing textile as in the previous year 584 crore-dollar textiles are imported (2013).

This literature review indicates that RMG sector of Bangladesh is now paying more attention to labor rights and unsafe working environment than the past. Consequently, many international buyers now demand orders from Bangladeshi garment industries. Therefore, an effective initiative (making labor wage up to 5500 taka) by the government in this regard has provided a basis for negotiating with buyers.

\section{ObJective OF The Study}

The objective of this study is to explicate the socio-business consideration of garment worker in Bangladesh with the help of different statistical measures and scale.

\section{DATA \& VARIABLES}

\section{Source of Data}

Fifty-three garment workers of five garment industries in Bangladesh fill up the questionnaires. The name of the garment industries are Dragon Garments, Dina Garments, Khalil Garments, Opash Garments and Chondropuri Garments. 


\section{Variables}

The variables are name, age, designation, salary, level of education, working experience in year, security, training and average working hour. Among them "name" and "designation" are string variables and others are numeric.

There are 53 garment workers in this research. The data of the first variable "name" is written according to the names in the questionnaires. Among them the first 10 workers are from Dragon Garments, the next 13 are from Dina Garments, the next 10 are from Khalil Garments, the next 10 are from Opash Garments and the last 10 are from Chondropuri Garments. The third variable "designation" is labeled as $1=$ line chip, $2=$ supervisor, $3=$ floor manager, 4 = cutting master, $5=$ worker, $6=$ operator, $7=$ ironman, $8=$ guard and $9=$ manager. The design masters are included in 4 . The helpers are included in 5 . The general manager (GM) and other managers are included in 9.

The fifth variable "level of education" is labeled as- $0=$ no education, 1 = before SSC, $2=$ SSC pass, 3 = HSC pass, $4=$ more than in HSC. The seventh variable "security" is labeled as $1=$ good, 2 = medium, 3 = bad. The eighth variable "training" is labeled as- $0=$ no, $1=$ yes. The ninth variable "average working hour" is labeled as $1=$ less than 10 hour, $2=10$ hour and more. The data of other variables are written according to the questionnaires.

\section{Software and Technical Support}

This study is conducted through the following packages of software: SPSS 17.0; MS Office 2007.

\section{RESULTS \& ANALYSIS}

\section{Descriptive Statistics}

There are no missing values in the data set. From descriptive statistics, we can see thatthere are 53 cases. The minimum values for age, salary, level of education, working experience in year, security, training and average working hour are 15, 2500, 0, 0.4, 1, 0 and 1 respectively. The maximum values are 52, 60000, 4, 20.0, 3, 1 and 2 respectively. The mean (average) values for garment workers are 26.98 years of age, 9560.38 Taka salary, education is up to SSC pass (2.34), 3.821 years of experience, medium security (1.45), training given to $50 \%$ workers $(0.53)$ and average working hour is 10 hours or more (1.83) respectively. That means on average the age of a garment worker is approximately 27 years. The average salary of a garment worker is approximately 9560 taka. The average level of education is SSC pass. Average working experience is approximately 4 years. The proper security given in the garment industries is medium on average. The training for better security is given to on average 50 percent workers. Finally, on average the workers have to maintain 10 hour and more working time.

The standard deviations (variation of the values) for garment workers are 7.102 years of age, 10168.850 Taka salary, and education stopped before SSC (1.372), 3.4527 years of experience, medium security (0.748) is given, training given to $50 \%$ workers $(0.504)$ and average working hour is less than 10 hour (0.379) respectively. That means the total dispersions of the values are these results. The descriptive statistics is given in the appendix section (Table 1.1).

\section{Frequency Tables}

The individual frequency tables are given here for age, designation, salary, education, experience, security, training and average working hour respectively. 
At first, in table 1.2 the frequency distribution of "age" is given. The variable is labeled after recoding as $1=$ less than 20 years, $2=20-30$ years and $3=30$ years and above. Here six people are aged less than 20 years, the maximum thirty five people are aged 20-30 years and 12 are aged 30 years and above.

In table 1.3 the frequency distribution of "designation" is given. The value labels of the variable "designation" after recoding are $1=$ worker, 2 = supervisor, 3 = guard and $4=$ authority. Here the maximum forty-one people are general workers, four are supervisors, two are guards and the rest six people are higher authorities.

In table 1.4 the frequency distribution of "salary" is given. The variable "salary" is labeled after recoding as 1 = less than 5000 taka, 2 = 5000-10000 taka and 3=10000 taka and above. The maximum twenty two people get less than 5000 taka as salary, seventeen people get 5000 to 10000 taka and fourteen people get 10000 taka and above.

In table 1.5 the frequency distribution of "education" is given. The variable "education" is labeled as "level of education". The value labels are 0 = no education, 1 = before SSC, $2=$ SSC pass, 3 = HSC pass and $4=$ more than HSC. Here two workers have no education, the maximum twenty people stopped their education before SSC, six people are SSC pass, eight people are HSC pass and seventeen are more than HSC passed.

In table 1.6 the frequency distribution of "experience" is given. The variable "experience" is labeled after recoding as "working experience in year". The value labels are $1=$ less than 6 months, $2=6-12$ months and $3=12$ months and above. The maximum forty-eight people have less than 6 months experience, three get 6 months to 1 -year experience and two get more than a year experience.

In table 1.7 the frequency distribution of "security" is given. The variable "security" is labeled as "how is the security?". The value labels are $1=\mathrm{bad}, 2=$ medium and $3=$ good. Thirty-seven people says they get bad security, eight people says they get medium and another eight says they get good security.

In table 1.8 the frequency distribution of "training" is given. The variable "training" is labeled as "if security training is given". The value labels are $0=$ no and $1=$ yes. Here we see that twenty-eight people say training is given for security and another twenty-five say they do not get any training. Obviously, the training is not fruitful enough.

In table 1.9 the frequency distribution of "average working hour". is given. The variable is labeled after recoding as "average working hour". The value labels are $1=$ less than $10 \mathrm{hr}$ and $2=10 \mathrm{hr} \&$ more. Nine people work less than 10 hour. Definitely, they are seniors. The maximum forty-four people work more than 10 hour that include general workers.

All frequency tables are given in the appendix section.

\section{RECOMMENDATIONS}

\section{Condition of Garment workers in Income and Economic sectors}

Garment workers are poorly paid in this sector. Because of sustained campaigning by women workers, women rights and human rights activists and other trade unionists in Bangladesh, the minimum wage for garment workers was raised in 2010 for the first time in four years. Receipt of wages in the garment industry depends on meeting an assigned production target. If production targets are met, a sewing operator's salary now starts at 3,861 taka (approximately $£ 32$ ) a month and a helper's wage at 3,000 taka (£25) a month. This amount is inadequate in meeting the minimum living standards in the urban areas. Besides the above, they get no other benefits or festival allowances. Recently the 
higher authorities of the garment industries have declared to pay 5300 taka per employee in spite of the government's decision of paying 5500 taka.

Women workers are employed in poorly paid jobs facing severe lab our rights violations and do not get their legal entitlements. They are also forced to work at night often exceeding 10 working hours that is a violation of the labor standard.

\section{Condition of Garment Workers in Social-political sectors}

Garment workers are also disadvantaged socially and politically. As for example, they face problem in the areas of accommodation, transport, and access to health treatment. Most of them are living in the urban slums and they have no access to government social protection measures like VGD and VGF cards in rural areas. Women workers have no right to form labor/trade union and therefore politically they have no power and voice to bargain with the factory owners. Existing situation also deter them from getting involved in any right based activities for their well-being.

\section{Condition of Garment Workers in Training sector}

To provide proper training to workers, supervisors and managers in the RMG sector to improve their capacity. Training is always considered as an effective instrument for upgrading skills and raising efficiency of human resource, which eventually ensures increased productivity. The entrepreneurs of the relevant sector but much more needs to be done have taken some initiatives. Necessary steps should be taken by both the public and the private sectors, and development partners to establish appropriate fashion and technology institutes. Improvement in working conditions and organizational environment can also result in increased productivity, which eventually renders these enterprises more competitive.

\section{Condition of Garment Workers in Security sectors}

In 24 September 2013 nearly 3.5 million garment workers in Bangladesh, recently faced industrial accidents and a staggering loss of life. They should get essential support to improve working conditions, strengthen labor inspection and upgrade building and fire safety at their workplaces and by providing training to workers, supervisors and managers in the RMG sector to improve their capacity to ensure workplace safety including the prevention of violence. One of the solutions central to the safety issue may be worker empowerment, at Rana Plaza where they were forced to work, despite imminent collapse reported on TV news the previous day. Entrepreneurs have to provide and to ensure a safe working environment for the workers where they can exercise their rights fully and satisfactorily. Recent tragedies in Dhaka's garment industry have highlighted the importance of improving safety standards and ensuring protection for factory workers.

\section{Condition of Women Workers in Maternity leave and Child Care Facility}

Bangladesh Labor Law guarantees all women workers a total of 16 weeks' paid maternity leave and in January 2011 the Prime Minister announced that maternity leave would be extended to six months. However, most women workers have little knowledge of their rights or of the necessary applications to employers or the doctor's certificates needed in order to claim those rights. The majority end up being fired by their employers when they become pregnant or sent on leave without payment. As a result many women are forced to work during the final stages of pregnancy in order to make ends meet, jeopardizing the health of both mother and child. 
Most of married women workers have to spend a big amount of time separated from their children due to long timework. Although Bangladeshi Labor Law requires every establishment with more than 40 women employees to provide a suitable room or rooms for the use of children under the age of six. The majority of women workers in the garment factories have no option but to send their children to stay slum house or to send their parents in rural areas, due to lake of child facilities in their workplace, depriving them of the right to breastfeed and of the enjoyment of bringing up their own children.

If there is more time and funding then in depth analysis can be done.

\section{REFERENCES}

Absar, S.S. (2001). "Problems Surrounding Wages; The Readymade Garments Sectors in Bangladesh", Journal LMD Labour and Management in Development, Volume 2, p. 7.

Ahamed, F. (2011). Improving Social compliance in Bangladesh's Ready-made Garments Industry, Ph.D Thesis, Faculty of Business, Economics and Law; La Trobe University, Australia.

Alam M.J., Mamun, M.Z. and Islam, N. (2004). “Workplace Security of Female Garments Workers in Bangladesh", Social Science Review, Volume 21, No. 2, pp. 191-200.

Bansari, N. (2010). Textile and Clothing Sector in Post MFA Regime: A Case from Bangladesh, Gender and Trade, Commonwealth Secretariat, http://www.genderandtrade.org

Chowdhury, Mannan M.A, Ali, Mahboob M., Rahman and Rubba (2006). “WTO, Post-MFA Era and the Bangladesh RMG Sector: An Assessment of Performance and Challenges", South Asian Journal of Management, January, 2006, http://www.allbusiness.com/legal/international-tradelaw-treaties-agreements

Dasgupta, S. (2002). "Attitudes towards Trade Unions in Bangladesh, Brazil, Hungary and Tanzania", Journal Article on International Labour Review, Vol. 14 (1), 2002.

Doshi, G. (2009). Textile and Apparel Industry in Turkey, http:/ / ezinearticles.com; viewed on 27/3/09

Hyde, Alan (2009). "The International Labour Organization in the Stag Hunt for Global Labour Rights", Law \& Ethics of Human Rights, Volume 3(2), http://www.bepress.com/lehr/vol3/iss2/art2

Khan, F.R. (2006). Compliance: Need of the hour in the apparel industry; Law \& our rights, Issue No. 249, August 05, 2006, http:/ / www.thedailystar.net/law, viewed on 15/8/2009

Khondker Nasreen (2002). "Garments Industry in Bangladesh, South Asia Multidisciplinary Advisory Team (SAAT)", International Labour Organization, New Delhi, India.

Kumar, A. (2006). "Bangladesh: Industrial Chaos Worsens Political Instability", South Asia Analysis Group, Paper No.1852, http:/ /www.southasiaanalysis.org, viewed on 05/09/2008.

Mahmud R.B (2012) Skills development in Bangladesh RMG sector, the News Today, http://www.newstoday.com.bd

Majumder, P.P. (1998). "Health status of the Garment workers in Bangladesh; Findings from a survey of employer and employees", Bangladesh Institute of Development Studies (BIDS), Dhaka, Bangladesh.

Moazzem, G.K. (2005). State of Compliance of the RMG Sector of Bangladesh, Research Fellow, Center for Policy Dialogue (CPD), http/cottonbangladesh.con/RMG.htm, viewed on 22/12/08

Morshed, M.M. (2007). "A study on Labour rights implementing in Ready-made garments (RMG) industry in Bangladesh", Bridging the gap between theory and practice, Theses collection, Centre for Asia Pacific Social Transformation Studies, (CAPSTRANS), University of Wollongong, 2007, http://ro.uow.edu.au/cgi/viewcontent.cgi? 
Priyo (2010). Present status of workers' rights at RMG sector, http:/ / priyo.com/blog/business/26070.html, viewed on 05/06/2010

Quaium , Ridwan (2012). "Positive Impacts and the Future of Ready-made Garments." Published by International Publications Limited, Topkhana Road, Dhaka, Al- Falah Printing Press.

Quddus, M. and Rashid, S. (2000). "Entrepreneurs and Economic Development: the remarkable story of garment exports from Bangladesh", Journal of Bangladesh Studies, 2000, Volume 2(1), pp. 65-66, The University Press Limited, Dhaka, Bangladesh, ISBN No. 9840515012.

Rahman, S. (2004). "Global Shift: Bangladesh Garments Industry in Perspective", Journal Asian Affairs, Volume 26(1), pp. 75-91.

Rashid, M. A. (2006). "Rise of readymade garments industry in Bangladesh: Entrepreneurial ingenuity of Public Policy", Paper presented at the workshop on Governance and Development organized by the World Bank and BIDS at Dhaka on 11-12 November 2006, http://notunprojonmo.com/wp-content/uploads/2011/06/READYMADE-GARMENTSINDUSTRY.pdf

Richard M. L, Fei Qin and Brause (2007). "Does Monitoring Improve Labour Standards? Lessons from Nike", Industrial and Labour Relations Review, Volume 1, p. 61, October, 2007, http:/ / web.mit.edu/polisci/research, viewed on 02/04/2010

Sarker, Md. Fouad Hossain (2011). "History of Garments industry in Bangladesh". http: / / forum.daffodilvarsity.edu.bd/index.php?topic=4706.msg21138\#msg21138

Shimu, S. D. (1999). “Garments Workers: Movement and Struggle”, Narigrantha Probarton, Dhaka, Bangladesh.

Stuart, B. and Kirsten, N. (2010). Decent work and poverty eradication: literature review and twocountry study, Ergon Associates Limited, 8 Cold bath Square, London, EC1R 5HL, www.ergononline.net, viewed on 28/11/2010

2008. Bangladesh Bank, Economic Trends, www.adb.org/documents/books/ado/2008/ BAN.pdf

2008. Daily Newspaper of Bangladesh (a) The Daily Star (3rd Feb, 2008) (b) The Daily Prothom Alo (31st Jan, 2008) (c) The New Nation (3rd Feb, 2008) (d)The Daily New Age (29th January, 2008) and The Daily Star (Dhaka and July 14th, 2006 by libcom),Thursday, January 24, 2008), Labour Unrest and Production halts in 6m RMG units.

2008. EPB Report on Bangladesh Garments Statistics and Future Challenge, http:/ / articles.textileclass.com/bangladesh- garments-statistics-and-future-challenge, viewed on 10/2010

2010. Approved Code of Practice Working Hours, Government of New South Australia, Safe Work SA, http:/ / www.safework.sa.gov.au

2010. Fair Work Australia, Commonwealth of Australia, http:/ / www.airc.gov.au/kirbyarchives/2009exhibition01.htm, viewed on 28/8/2010

2011. BGMEA, Leading to Bangladesh prosperity, http:/ /bgmea.com.bd/home/pages/TradeInformation

2013. Bangladeshi RMG Sector, Wikipedia: The Free Encyclopedia, Wikipedia Foundation.

2013. Shafin Fattah. The Daily Star. Suspension of US GSP: What does this mean for Bangladesh? (Published: Saturday, June 29, 2013) 


\section{Appendix}

Table 1.1: Descriptive Statistics

\begin{tabular}{|c|c|c|c|c|c|}
\hline Variables & $\mathrm{N}$ & Minimum & Maximum & Mean & Std. Deviation \\
\hline age & 53 & 15 & 52 & 26.98 & 7.102 \\
\hline salary & 53 & 2500 & 60000 & 9560.38 & 10168.850 \\
\hline level of education & 53 & 0 & 4 & 2.34 & 1.372 \\
\hline working experience in year & 53 & .4 & 20.0 & 3.821 & 3.4527 \\
\hline how about the security? & 53 & 1 & 3 & 1.45 & .748 \\
\hline if security training is given & 53 & 0 & 1 & .53 & .504 \\
\hline average working hour & 53 & 1 & 2 & 1.83 & .379 \\
\hline Valid N (listwise) & 53 & & & & \\
\hline
\end{tabular}

Table 1.2: Frequency Distribution of "age"

\begin{tabular}{|c|c|c|c|c|c|}
\hline \multicolumn{2}{|c|}{} & Frequency & Percent & Valid Percent & Cumulative Percent \\
\hline Valid & less than 20 years & 6 & 11.3 & 11.3 & 11.3 \\
\cline { 2 - 6 } & $20-30$ years & 35 & 66.0 & 66.0 & 77.4 \\
\cline { 2 - 6 } & 30 years and above & 12 & 22.6 & 22.6 & 100.0 \\
\cline { 2 - 6 } & Total & 53 & 100.0 & 100.0 & \\
\hline
\end{tabular}

Table 1.3: Frequency Distribution of "designation"

\begin{tabular}{|c|c|c|c|c|c|}
\hline \multicolumn{2}{|c|}{} & Frequency & Percent & Valid Percent & Cumulative Percent \\
\hline \multirow{4}{*}{ Valid } & worker & 41 & 77.4 & 77.4 & 77.4 \\
\cline { 2 - 6 } & supervisor & 4 & 7.5 & 7.5 & 84.9 \\
\cline { 2 - 6 } & guard & 2 & 3.8 & 3.8 & 88.7 \\
\cline { 2 - 6 } & authority & 6 & 11.3 & 11.3 & 100.0 \\
\cline { 2 - 6 } & Total & 53 & 100.0 & 100.0 & \\
\hline
\end{tabular}

Table 1.4: Frequency Distribution of "salary"

\begin{tabular}{|c|c|c|c|c|c|}
\hline \multicolumn{2}{|c|}{} & Frequency & Percent & Valid Percent & Cumulative Percent \\
\hline \multirow{3}{*}{ Valid } & Less than 5000 tk & 22 & 41.5 & 41.5 & 41.5 \\
\cline { 2 - 6 } & $5000-10000$ tk & 17 & 32.1 & 32.1 & 73.6 \\
\cline { 2 - 6 } & 10000 tk \& above & 14 & 26.4 & 26.4 & 100.0 \\
\cline { 2 - 6 } & Total & 53 & 100.0 & 100.0 & \\
\hline
\end{tabular}


Table 1.5: Frequency Distribution of "education"

\begin{tabular}{|c|c|c|c|c|c|}
\hline \multicolumn{2}{|c|}{} & Frequency & Percent & Valid Percent & Cumulative Percent \\
\hline \multirow{4}{*}{ Valid } & No education & 2 & 3.8 & 3.8 & 3.8 \\
\cline { 2 - 6 } & Before SSC & 20 & 37.7 & 37.7 & 41.5 \\
\cline { 2 - 6 } & SSC pass & 6 & 11.3 & 11.3 & 52.8 \\
\cline { 2 - 6 } & HSC pass & 8 & 15.1 & 15.1 & 67.9 \\
\cline { 2 - 6 } & HSC a \& above & 17 & 32.1 & 32.1 & 100.0 \\
\cline { 2 - 6 } & Total & 53 & 100.0 & 100.0 & \\
\hline
\end{tabular}

Table 1.6: Frequency Distribution of "experience"

\begin{tabular}{|c|c|c|c|c|c|}
\hline \multicolumn{2}{|c|}{} & Frequency & Percent & Valid Percent & Cumulative Percent \\
\hline \multirow{3}{*}{ Valid } & Less than 6 months & 48 & 90.6 & 90.6 & 90.6 \\
\cline { 2 - 6 } & 6 months to 1 year & 3 & 5.7 & 5.7 & 96.2 \\
\cline { 2 - 6 } & More than 1 year & 2 & 3.8 & 3.8 & 100.0 \\
\cline { 2 - 6 } & Total & 53 & 100.0 & 100.0 & \\
\hline
\end{tabular}

Table 1.7: Frequency Distribution of "security"

\begin{tabular}{|c|c|c|c|c|c|}
\hline \multicolumn{2}{|c|}{} & Frequency & Percent & Valid Percent & Cumulative Percent \\
\hline \multirow{4}{*}{ Valid } & Good & 37 & 69.8 & 69.8 & 69.8 \\
\cline { 2 - 6 } & Medium & 8 & 15.1 & 15.1 & 84.9 \\
\cline { 2 - 6 } & Bad & 8 & 15.1 & 15.1 & 100.0 \\
\cline { 2 - 6 } & Total & 53 & 100.0 & 100.0 & \\
\hline
\end{tabular}

Table 1.8: Frequency Distribution of "training"

\begin{tabular}{|c|c|c|c|c|c|}
\hline \multicolumn{2}{|c|}{} & Frequency & Percent & Valid Percent & Cumulative Percent \\
\hline \multirow{3}{*}{ Valid } & Yes & 25 & 47.2 & 47.2 & 47.2 \\
\cline { 2 - 6 } & No & 28 & 52.8 & 52.8 & 100.0 \\
\cline { 2 - 6 } & Total & 53 & 100.0 & 100.0 & \\
\hline
\end{tabular}

Table 1.9: Frequency Distribution of "average working hour"

\begin{tabular}{|c|c|c|c|c|c|}
\hline \multicolumn{2}{|c|}{} & Frequency & Percent & Valid Percent & Cumulative Percent \\
\hline \multirow{3}{*}{ Valid } & Less than $10 \mathrm{hr}$ & 9 & 17.0 & 17.0 & 17.0 \\
\cline { 2 - 6 } & $10 \mathrm{hr} \&$ more & 44 & 83.0 & 83.0 & 100.0 \\
\cline { 2 - 6 } & Total & 3 & 100.0 & 100.0 & \\
\hline
\end{tabular}

